\title{
Resiliência e sua Importância no Desenvolvimento Integral da Pessoa ${ }^{1}$
}

\begin{abstract}
Javier Fiz Perez²
${ }^{1}$ Palestra proferida pelo Prof. Javier Fiz Perez no II Seminário Interdisciplinar de Pesquisa realizado no dia 16 de maio de 2017 na Universidade de Taubaté, em parceria com o UNIS Centro Universitário do Sul de Minas.

2 Professor de Psicologia (Psicologia do Desenvolvimento e Formação: Psicologia Clínica e Organizacional) na Universidade Europeia de Roma, onde trabalha também como Delegado para o desenvolvimento da investigação internacional e como co-diretor científico do Laboratório de Psicologia Aplicada no domínio da Psicologia Organizacional.
\end{abstract}




\section{A RESILIÊNCIA É INATA OU ADQUIRIDA?}

A resiliência é o resultado do produto do relacionamento ternário entre corpo-mente-ambiente, em outras palavras, a interação sistêmica entre os fatores fisiológico, psicológico e social.

Numerosos estudos demonstraram a existência de uma relação entre os aspectos fisiológicos e resiliência, sendo que ainda não está clara a participação dos aspectos genéticos. Portanto, resta ainda esclarecer qual a importância da influência genética.

Existem muitos aspectos intimamente relacionados à resiliência inata, como - por exemplo - o gênero. O gênero masculino parece ser menos resistente ao estresse psicológico (Bernard, 1991) e mais propenso a desenvolver transtornos de conduta, como resultado de por exemplo estar longe de casa (Belsky e Ruínas, 1988), em situações de separação e divórcio (Hettherington, 1991) ou acontecimentos desagradáveis e traumáticos (Gamerzy \& Rutter, 1985).

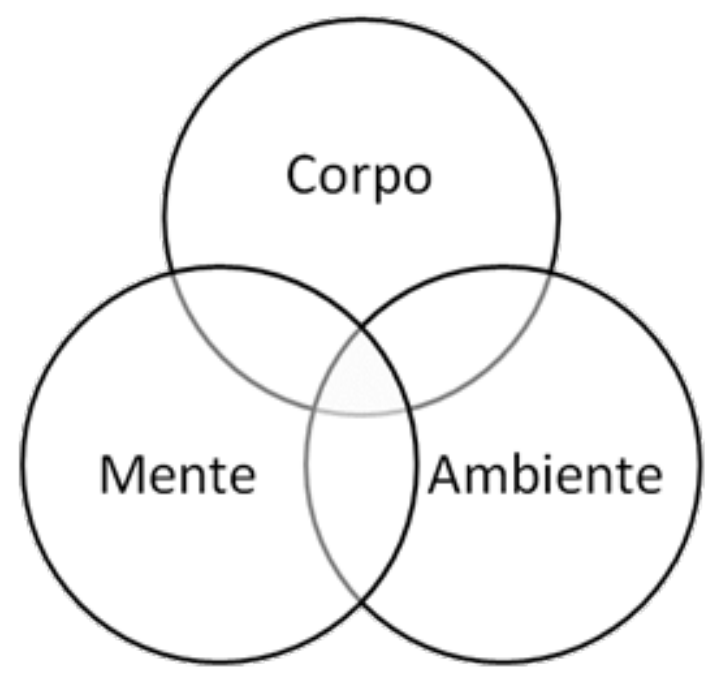

Figura 1 - A resiliência e sua relação Corpo-Mente-Ambiente

No que diz respeito à condição médica geral, as crianças resilientes parecem ser mais saudáveis e menos propensas à doenças, especialmente aquelas com um físico robusto, energia acima da média e padrão regular de alimentação e sono (Rodhes \& Brown, 1991; Felsman 1989; Heizer, 1995; Murphy, 1987; Werner, 1990).

Em relação aos aspectos psicológicos de natureza genética, numerosos estudos confirmaram a existência de uma relação entre a inteligência e a capacidade de resiliência, e, em particular, um maior inteligência em indivíduos resilientes (Gjerde, Bloco \& Block, 1986; Moffitt, \& Stouthamer-Loeber, 1993; Taylor, 1994).

Uma questão importante em torno do qual o debate científico foi muito aquecido no campo da psicologia diz respeito à interpretação - não única - sobre a natureza da resiliência.

Na literatura duas posições são rastreáveis. A primeira considera a resiliência como um fator de personalidade inata. Esta posição foi desenvolvida a partir dos trabalhos de Block \& Block $(1980,1996)$ em que denominam ego-resiliência, um conjunto de características que refletem a independência e a força do caráter, bem como a adaptabilidade da operação em resposta a diferentes circunstâncias ambientais. Consideram que existe traço constitutivo de cada ser humano que pré-existe, antes da exposição a eventos dolorosos e que, desempenham um papel de detecção da personalidade resiliente. 
A segunda posição identifica a resiliência como um processo dinâmico, que envolve uma adaptação positiva dentro de um ambiente significativamente adverso (Luthar, 2000) implicando, assim, dois pressupostos fundamentais: a exposição a um risco significativo; e uma tendência positiva, apesar da ameaça sofrida (Luthar \& Zigler, 1991; Masten, Melhor \& Garmezy, 1990; Rutter, 1990; Werner \& Smith, 1992).

Os termos ego-resiliência e resiliência foram usados por um longo tempo e erroneamente como conceitos intercambiáveis; na verdade, eles diferem em pelo menos duas dimensões (Luthar, 1996): o ego-resiliência é uma característica da personalidade do indivíduo, enquanto que a resiliência é um processo dinâmico de desenvolvimento; o ego-resiliência não requer a exposição ao risco, enquanto a capacidade de resiliência, por definição, a pressupõe. Masten (1994). Considerando os aspectos da terminologia, recomenda que o construto resiliência seja utilizado apenas quando se faz referência à manutenção de uma adaptação positiva em condições adversas e, por conseguinte, adverte contra o uso indiscriminado do termo "resiliência", o que remete implicitamente a um traço de personalidade.

\section{RESILIÊNCIA É UM TRAÇO OU UM PROCESSO?}

A diferença entre ego-resiliência e processo de resiliência consiste no fato de que o primeiro está presente mesmo quando não há exposição ao risco, enquanto que no segundo a adversidade constitui precisamente o combustível inicial do processo.

Nesta perspectiva, a resiliência é a capacidade do homem que, inseparavelmente esteja consciente de estar em uma situação negativa, mobiliza recursos internos e externos (fatores de proteção para atuar como um contrapeso para os fatores de risco), e assim é capaz de superar esta situação.

Em uma primeira fase de estudos, com base na análise teórica e aplicação não precisamente madura, surge forte ambiguidade, que foi criada em torno do conceito resiliência, considerando-o intercambiável com o ego-resiliência. Há, portanto, também o risco de se usar indevidamente o termo resiliência como sinônimo do termo resistência.

Resistência é um fator de personalidade estável (adjacente ao ego-resiliência) que atua como força oponente a um agente estressor forte (Kobasa, Maddi, Khan, 1982) e pode suportar adversidade, que não implica em mudança, ao contrário do que acontece com a resiliência que facilita a construção, até mesmo uma re-construção da trajetória de vida, propiciando à pessoa a capacidade de avançar (Vanistendael \& Lecomte, 2000) por meio da mudança. 


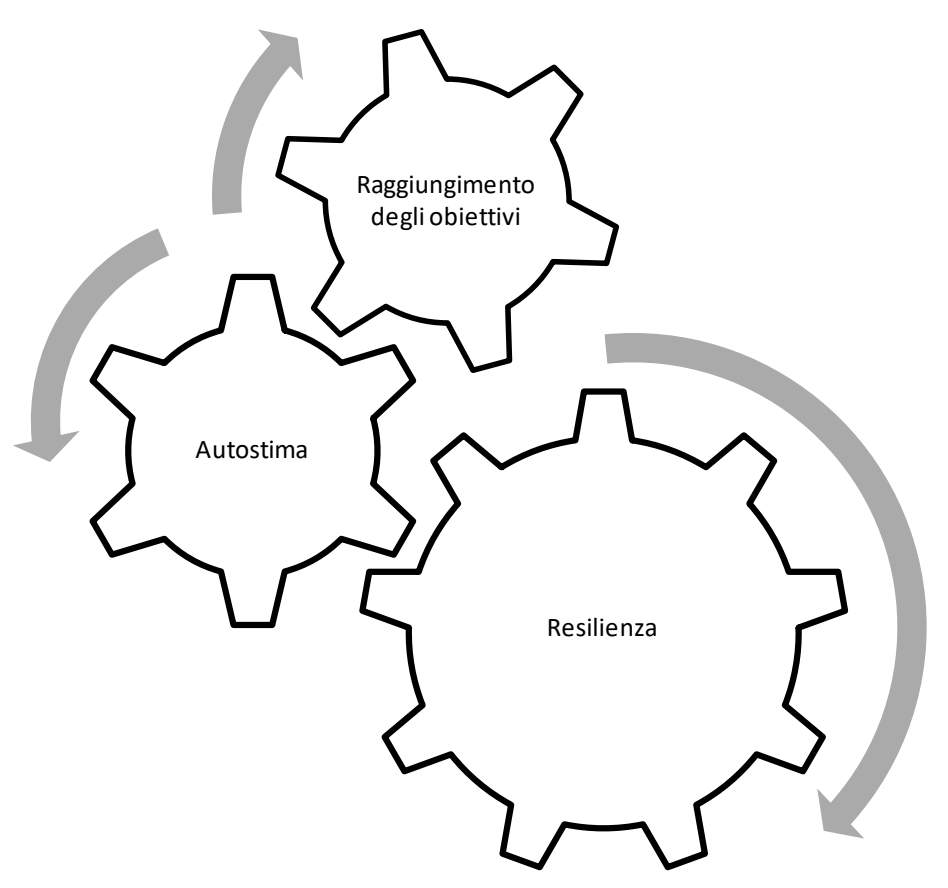

Figura 2 - Objetivo, Autoestima e Resiliência

Groteberg (1995) argumenta que se pode considerar a mudança a partir da aquisição de novas habilidades, tais como a capacidade de se tornar mais forte para sair de eventos traumáticos transformando-os em objetivos de vida e seus significados.

O direcionamento para a superação de um evento negativo pode ser uma oportunidade de crescimento e aprendizagem (Linely e José, 2004). Além disso, como já foi destacado por Emiliani (1995), a realização dos seus objetivos favorece um sentimento renovado de eficácia pessoal e do auto aperfeiçoamento: mecanismos que, por sua vez, através de uma ação circular, acelera o processo de resiliência, completando o desenvolvimento.

De acordo Luthar \& Cicchetti (2000), a resiliência está associada a um traço de personalidade estável que certamente favorece a identificação de pessoas resilientes e não-resilientes, mas essa perspectiva também é um limite fundamental para a pesquisa, uma vez que é difícil pensar em poder intervir em situações sobre assuntos "em que não se têm" o que é preciso para superar a adversidade.

Ao longo da história, a análise dos efeitos vivenciados pelo homem que enfrentou um evento traumático passou por várias etapas: a primeira parte da perspectiva, dominada no modelo médico tradicional como "main effect approach", que envolve a identificação de um fator nocivo patogênico especial como o único responsável por um quadro sintomático específico - e a capacidade de recuperação é considerada proporcional ao tamanho do dano - (Ajuriaguerra \& Marcelli, 1982), assumindo uma abordagem cumulativa e multi-fatorial, acompanhada por uma lógica somatória que permite um diagnóstico diferencial por meio da classificação dos índices de desconforto e prevê uma probabilidade de recuperação correspondente à quantidade de elementos positivos capazes de gerar estados de equilíbrio (Anthony, Chiland \& Koupernik, 1982).

Atualmente este modelo foi reformulado em favor da ideia de causalidade dada pela sinergia de vários elementos que influenciam uns aos outros, e por isso aparece como algo mais do que uma simples soma (Rutter, 1990). 
Em conclusão: a capacidade do indivíduo gerar ordem e direção às suas ações de uma forma muito pessoal, é o resultado da interação de seu genótipo, ou organização genética e biológica, responsável pelo seu tamanho corporal e base psíquica, com o ecotipo ou organização social em que está inserido que, geralmente, se dá no seio da família.

A este respeito Baldwin e Cole (1990), propuseram uma distinção entre fatores distais e proximais, assumindo entre os dois sistemas, reciprocidade dinâmica para as quais os fatores proximais exercem a sua influência direta sobre os indivíduos e podem funcionar como mediadores comparados aos fatores distais, ampliando ou reduzindo o risco de danos no desenvolvimento da pessoa.

Um aspecto que gera confusão deriva do uso do termo ocasional "criança resiliente, também" entre os estudiosos, que conceituam a resiliência como um processo dinâmico (Masten et al, 1990;. Rutter, 1993; Werner, 1984).

Deve-se observar, entretanto, que o termo "criança resiliente", neste caso, não se refere a um atributo pessoal discreto, como inteligência ou empatia; Esta definição foi usada em referência a duas condições coexistentes no processo de resiliência - a presença de uma ameaça para o bem-estar da criança e a presença de uma boa adaptação em face da adversidade encontrada (Richters \& Weihtraub, 1990; Luthar, 1993).

De acordo Luthar e colegas de trabalho (2000), parece ser necessário para sugerir que os investigadores façam uso cauteloso da terminologia, com clara indicação da referência a resiliência como um processo dinâmico e não como um traço de personalidade estável.

Dentro deste debate é de particular interesse a posição de Richardson, segundo a qual a resiliência: é a energia, é a força que Ihes permite produzir a tendência de atualização/mudança, que permite, por meio das dificuldades e rompimento de um equilíbrio existencial, acesso à motivação e reorienta o pensamento e o crescimento pessoal, altruísmo e a consciência em harmonia com o espírito (Richardson, 1990, p. 33).

Na definição de resiliência, Richardson não defende uma classificação absolutista, mas ilustra a natureza dual da resiliência, usando a expressão para indicar um conjunto de características já possuídas, e que, eventualmente, podem ser desenvolvidas, indicando o processo de recuperação em situação traumática.

\section{A RESILIÊNCIA É ESTÁVEL?}

Como apontado por Anaut (2003), a resiliência pode ajudar a superar as dificuldades para que a pessoa possa emergir mais forte e consciente, mas não a torna invencível ou invulnerável à adversidade.

Aqueles que conseguiram retomar sua trajetória após duro golpe causado pela vida são pessoas que encontram em si mesmo, nas relações humanas e no contexto de sua realidade, os elementos necessários - e o poder - para superar as adversidades, e isso aconteceu graças à disponibilidade da pessoa naquele tempo, sendo uma combinação de vários êxitos, mas nem sempre replicáveis.

No entanto, é necessário distinguir na resiliência os recursos, as estratégias e os estilos. Os recursos de resiliência incluem tanto aspectos da própria pessoa quanto do meio ambiente e se relacionam com os elementos a partir dos quais um indivíduo pode obter a força e as ferramentas para lidar com um evento traumático. Obviamente, também podem ser extremamente variáveis, de forma independente em relação à vontade do sujeito.

As estratégias de resiliência são fundamentadas nas atitudes resilientes que a pessoa utiliza quando vivencia uma situação traumática, podendo variar no tempo, além de depender da disponibilidade dos re- 
cursos de resiliência.

O estilo de resiliência é a tendência de uma pessoa a agir de forma consistente frente aos eventos problemáticos ou traumáticos. Além disso, o estilo de resiliência reflete o modo de representação da vida (coerente com as crenças, com os valores e com os objetivos) e o modo de se relacionar com eventos traumáticos.

Enquanto as estratégias de resiliência podem variar, os estilos de resiliência podem ser bastante estáveis e - consequentemente - faz sentido conhecê-los para poder "prever" como o sujeito pode se comportar frente aos potenciais eventos traumáticos. Além disso, devido à sua estabilidade, faz sentido também preparar as pessoas para desenvolver estilos mais resistentes.

Além disso, Luthar (1993) afirma que a resistência depende do contexto de referência. Um indivíduo pode expressar as habilidades resilientes em um determinado contexto, mas não ser capaz de expressá-los em outro. Isso significa que ele também poderia ter alguma forma de estabilidade temporal na sua construção, mas é sempre necessário considerar a especificidade situacional.

Na dimensão relacional da resiliência, destacam-se as atividades da pesquisa de Friburgo (2003) - investigação dos fatores pessoais - por meio da Escala de Resiliência para adultos, com mais de 19 itens de reserva (33 no total) para a síntese de três fatores: habilidades sociais, coesão familiar e recursos sociais. 0 autor parece interpretar e condensar o pensamento compartilhado por muitos outros estudiosos (Garmezy, 1985; Werner \& Smith, 1982; Lucey, 1992; Walkerdine, 1997; Vaillant G, 1993;. Luthar et al, 2000), que defenderam a ideia de resiliência como a integração de produtos das dimensões biológicas e psicológicas, com o apoio emocional da família e da cultura de pertença.

\section{O QUE SE ENTENDE POR “ATITUDE” RESISTENTE?}

Na psicologia, uma atitude é uma estrutura psíquica constituída pela associação da memória com a representação de um objeto e sua avaliação. A atitude, de acordo com um cenário generalizado (Rosenberg e Hovland, 1960), é formada por três componentes, incluindo as dimensões: cognitiva, afetiva e conativa (ou comportamental).

Da mesma forma, também a construção de resiliência refere-se a dimensões tais como cognição, emoção e conação.

Alguns estudos (Kaufman, Cook, Arny, Pittinsky e Jones, 1994) mostraram como essas três dimensões podem estar por vezes em desacordo, de modo a gerar dúvidas sobre a exatidão e a integridade da construção da resiliência.

A existência de irregularidades entre os três domínios não invalida a construção de resiliência, mas coloca pesquisadores na posição de ter que especificar o tamanho a que se referem. 


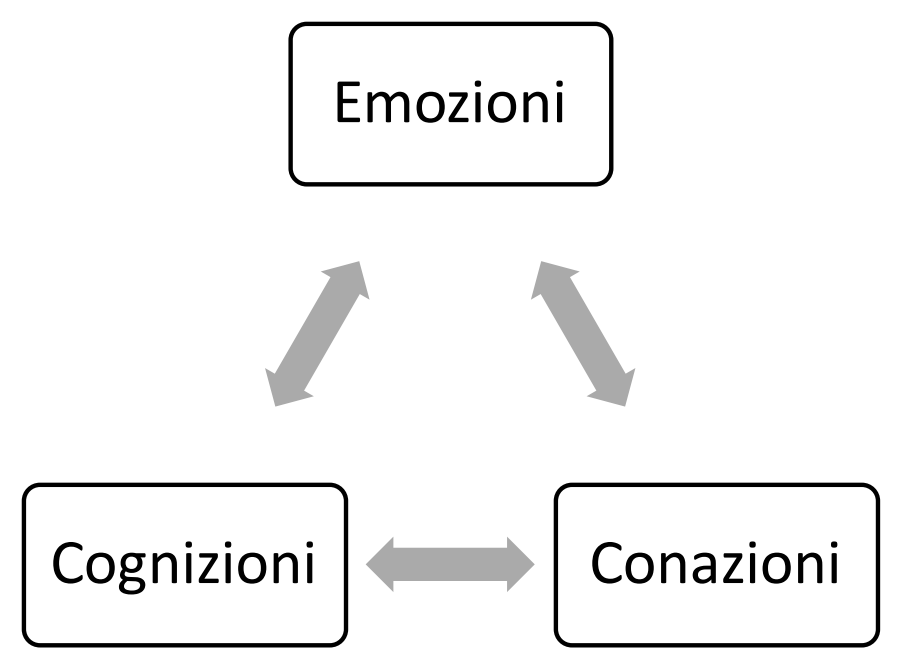

Figura 3 - As três dimensões da construção da resiliência

Em outras palavras, é necessário compreender que resiliência é um conceito complexo, que requer indicação adequada da dimensão de referência, distinguindo, por exemplo, entre: resiliência educacional (Wang e Gordon, 1994), emocional ou comportamental (Carpentieri , et al., 1993), com a intenção de proporcionar maior precisão na terminologia utilizada na literatura. Embora para alguns autores (Luthar et al., 2000) as três dimensões parecem estar intimamente relacionadas no desenvolvimento de um comportamento resiliente, sendo importante enfatizar, que para a análise da atitude de resposta a um evento traumático, é necessário analisar pensamentos e cognições (representação daquele evento traumático) emoções e comportamentos (tanto imediatos quanto posteriores).

\section{QUAL É O PAPEL DA FAMÍLIA?}

A perspectiva sistêmico-relacional identifica a família como um conjunto organizado de interações sociais em que todos os membros são, ao mesmo tempo, interdependentes e inter-relacionados (Bowen, 1978; Minuchin, 1985).

A família é a unidade emocional em que os comportamentos dos indivíduos são mutuamente influenciados pela organização da família como um sistema. Na família, cada membro é obrigado a desempenhar um papel particular (White \& Klein, 2002).

A abordagem sistêmico-relacional foi utilizada para a compreensão da psicopatologia da família. Contrariamente à perspectiva individualista da psiquiatria, a abordagem sistêmica relacional conceitua psicopatologia como um sintoma do mau funcionamento do sistema familiar, em vez de um sintoma de um distúrbio pessoal (Bowen, 1978). Por outro lado, afirma-se que a psicopatologia de uma família inicia-se por um modelo de interação circular, que tem um impacto sobre o funcionamento do sistema da família, bem como os subsistemas, que, por sua vez, afetam o indivíduo (Bowen, 1978). Para Walsh, 1998, resiliência pode estar integrada a um quadro mais amplo de análise do contexto familiar, de acordo com a perspectiva sistêmico-relacional. Hawley e DeHaan (1996) definiram a resiliência familiar como o caminho para adaptação do sistema familiar frente eventos estressantes, tanto no presente quanto ao longo do tempo.

A resiliência é uma característica da família funcional e um dos mecanismos que protegem o seu bom funcionamento. Para os indivíduos, existem fatores de risco e os fatores de proteção (Walsh, 2002). 
De acordo com o princípio da interdependência e da ligação, na abordagem sistêmico-relacional, uma condição de psicopatologia de um membro da família tem impacto sobre os outros indivíduos do sistema operacional (Gullone \& Hughes, 2008).

A pesquisa sugere que adolescentes filhos de pais deprimidos tendem a ter altas taxas de transtornos psiquiátricos, particularmente depressão, em comparação com os adolescentes de pais saudáveis (Biedarman, 2001). Da mesma forma, os pais de adolescentes deprimidos relatam níveis mais elevados de sintomas de estresse e depressão (Windle \& Davies, 1997).

De maneira geral, os adolescentes inseridos em contextos familiares em que existem problemas de comunicação (Carbonell, Reinherz, \& Gioconia, 1998), ou níveis elevados de conflito familiar (Cole \& McPherson, 1993, Harold et al., 1997), são os com maior risco de problemas psicológicos.

Olsson et al, 2003 apontam que a coesão familiar, a comunicação e o apoio dos pais estão associados a níveis mais baixos de problemas psicológicos (Barber \& Buehler, 1996; Carbonell, Reinherz, \& Gioconia, 1998), e tendência ao suicidio (Perkins \& Jones, 2004). A capacidade de uma família para ser coesa fortalece a capacidade dos membros para aliviar a dor e promover a resistência à depressão. Embora a família desempenhe papel central no desenvolvimento da resiliência de indivíduos é igualmente verdade que a resiliência foi inicialmente concebida, precisamente em relação à capacidade de algumas pessoas estar em situação de "descontinuidade", em relação à sua família de origem e não para desenvolver comportamento patológico, apesar da exposição direta a família.

\section{A RESILIÊNCIA DIZ RESPEITO APENAS AOS INDIVÍDUOS?}

De acordo com Richardson (2002), o processo de resiliência envolve não somente o indivíduo, mas pode ser considerado na dinâmica do casal, da família, da escola, do trabalho e das organizações e de contextos mais amplos de toda a comunidade. De modo mais geral, é possível falar de resiliência em relação a todos os sistemas possíveis. Kenneth Boulding, um dos mais ferrenhos defensores da teoria geral dos sistemas, conceituou o mundo como uma hierarquia ordenada de sistemas.

É evidente que, com exceção do contexto, é possível em todos os casos referir-se à construção de resiliência. Em particular, você pode usar este conceito em relação às organizações sociais, considerando-as como a integração holística de seus membros.

Você pode falar sobre a resistência de um casal, de uma família, de um grupo ou de uma organização (de trabalho ou não). Usando o sistema mais simples (a dupla ou o casal) é evidente que a resiliência não é a simples soma (ou média) da resiliência de cada um dos dois componentes, mas algo diferente e mais complexo. 


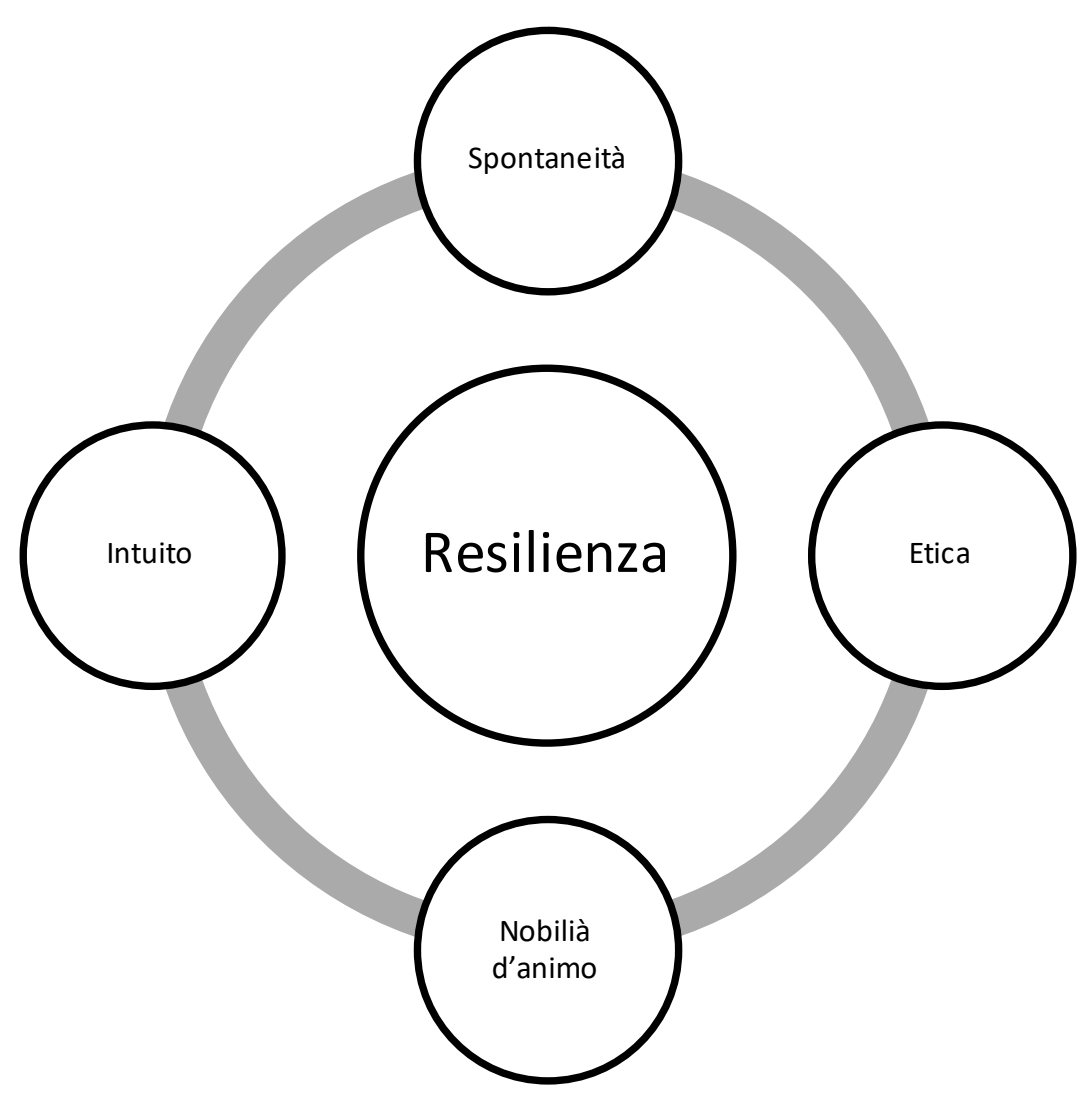

Figura 4 - As características de resiliência de acordo com Richardson

Uma verdadeira mistura entre os fatores de proteção e risco mútuos combinada com fatores sistêmicos de ordem mais elevada (as que se referem ao casal) e em relação constante entre elas. Da mesma forma, também para a família ou grupo, resiliência não é uma soma simples, mas o resultado da relação e da interação cada vez maior e mais complexa entre os vários componentes.

De particular interesse, aparece o estudo da resiliência organizacional, entendida como a capacidade de uma organização (de trabalho ou não) para superar eventos difíceis por meio da mudança das pessoas ou do ambiente circundante. Em nosso ponto de vista, mesmo nas organizações é possível usar o modelo proposto por Richardson, vez que considera a categorização das características do sistema resiliente. Em relação a este último, podemos dizer que uma organização resiliente é espontânea, ética, intuitiva e possui "nobreza" de princípios.

Uma organização "espontânea" tem altos níveis de abertura à aprendizagem e de experimentação, combinado com boa dose de energia e capacidade de inovação. A dimensão ética expressa-se, no campo da organização, por uma forte integridade e lealdade dos membros e dos que usufruem dos bens ou dos serviços oferecidos por essa organização. Uma organização intuitiva assume receptividade estreita com as características e as mudanças que ocorrem em seu contexto organizacional. Além disso, está ligada à capacidade de implementar rapidamente o comportamento considerado apropriado.

Para uma organização, a "nobreza" esta na visão saudável ligada ao desejo de deixar uma contribuição para a sociedade da qual faz parte. 


\section{VOCÊ PODE AUMENTAR A RESILIÊNCIA?}

Segundo alguns autores (Pert, 1997; Richardson, 2002), experiências negativas, crenças limitantes e trauma podem acarretar um "curto-circuito" no sistema de energia humana. Este sistema é constituído dos sistemas nervosos central e periférico, juntamente com os plexos intramurais do intestino, o sistema endócrino, o sistema imunológico e é a base estrutural em que se transita a informação bioquímica emocional.

A redescoberta de uma força interior ou a exposição a expectativas externas ou recursos imprevistos podem mitigar a extensão de um estado de mal-estar ou até mesmo determinar a remissão completa dos sintomas (Richardson, 2002).

Num estudo realizado com base no modelo de Richardson (1990) entre os pacientes que sofrem de diabetes alimentar, envolveu-se 67 indivíduos aleatórios dos quais 30 foram escolhidos para o programa de resiliência e 37 selecionados para um programa de educação baseado no modelo de informação. A avaliação dos resultados foi realizada após três e seis meses a partir do início do curso, por meio da investigação de parâmetros fisiológicos e comportamentais (hemoglobina glicosilada, circunferência abdominal, mudança de hábitos alimentares e frequência de exercícios) e variáveis psicológicas (auto eficácia, locus de controle de apoio social e pró-atividade).

O grupo submetido ao programa de resiliência (modelo Richardson), em comparação com o grupo decontrole mostrou alteração significativa em relação a parâmetros de comportamento (tais como os hábitos alimentares e o aumento da frequência de atividade física) com a conseqüente redução da cintura.

Mesmo em comparação com o parâmetro da hemoglobina glicosilada, embora não tenha sido verificada uma diminuição significativa estatisticamente, houve uma tendência de melhoria. Além disso, o mesmo grupo relatou nível médio mais elevado em comparação com o grupo de controle dos parâmetros das variáveis psicológicas (auto-eficácia, o locus of conrol, apoio social e pró-atividade), demonstrando que, ao se permitirem ter a consciência em relação ao suas habilidades não desenvolvidas, as pessoas conseguiram melhorar as relações interpessoais, assim, é possível dizer que se pode escolher para si as melhores estratégias para lidar com o estresse sobre a doença, o que contribui para influenciar de forma positiva a sua saúde (Bradshaw, Richardson, Kumpfer, Carlson, Stanchfield, 2007).

O fortalecimento dos poucos ou não explorados potenciais individuais tornou-se atividade de Richardson, que afirma que uma intervenção baseada no reforço da resiliência deve facilitar antes de tudo a pessoa a se libertar das pressões e convenções culturais e sociais, o que inevitavelmente afetam e limitam o sujeito, especialmente nos processos de avaliação, tomada de decisão e resolução de problemas.

De acordo com Richardson (2002), um terapeuta deve ajudar o paciente a resolver a depressão, a ansiedade, o ressentimento e os estados psicológicos que geram confusão e desorientação, em detrimento do pedido de racionalidade, e, finalmente, deve motivá-lo a descobrir esses recursos dentro dele mesmo, para ajudá-lo a reagir frente aos eventos adversos, com calma, ponderação, coragem, inteligência, equilíbrio e aceitação e desenvolver uma resiliência crescente. Uma intervenção psicológica, por essa ótica, deve, sobreturo, contribuir para o desenvolvimento de um locus de controle interno, auto-eficácia interna e renovada, para permitir escolhas independentes e dirigir o curso dos acontecimentos, estando no controle de suas ações.

Richardson (2002) admite que, embora sob aspectos distintos, há muitos autores do passado ou seus contemporâneos, que tratam de resiliência na medida em que desenvolveram algumas técnicas terapêuticas válidas para superar as condições traumáticas e a capacitação de recursos internos (primeira Freud 1900, e, em seguida, Jung de 1935; Piaget, 1950; Kholberg, 1970; Moore, 1975; Seligman, 1990; Bandura, 1997; Csikszentmihalyi, 1998). O trabalho de Richardson não somente confirma a importância, mas, sobretudo, a neces- 
sidade de estruturar programas de treinamento capazes de desenvolver e de fortalecer uma atitude flexível nas pessoas.

\section{VOCÊ PODE AVALIAR A RESILIÊNCIA?}

Para alcançar uma avaliação cuidadosa da construção da resiliência é essencial ter um quadro teórico de referência claro e um design detalhado do processo de validação. Em relação ao modelo teórico, é indispensável projetar a intervenção de avaliação, em particular, em relação aos aspectos de definição.

Para dispor de um quadro teórico, dentro da ampla gama de possibilidades disponíveis na literatura, é possivel articular intervenções de avaliação e de melhoria. Em geral, a avaliação é um processo complexo, cujo objetivo é a formulação de um juízo de um sujeito, de um objeto ou de um processo, dividido em dois momentos distintos entre eles: a coleta de dados e de informações e a elaboração de um julgamento avaliativo (Bulgarelli, 1996). A avaliação, de acordo com Cronbach (1982), é um evento político que, na maioria dos casos, é prática em um ambiente em que atuam diferentes grupos de interesse que tendem a proteger e defender suas posições e as das pessoas as quais representam.

Por essa razão, as avaliações expõem, de forma semelhante, direta ou indiretamente, tanto o avaliado quanto o avaliador (Avallone, 1996). Em última análise, um processo de avaliação deve produzir suporte para o processo de tomada de decisão, reduzindo a complexidade do nível do evento (Bezzi, 2001).

Na prática, a avaliação fornece a decisão, traz um resumo do modelo de evento estimado que lhe permite tomar decisões. Por essa razão, um avaliador é chamado a reduzir, simplificar e sintetizar uma realidade complexa, formulando um ou vários juízos sobre determinado caso.

Uma decisão não pode - por definição - ser objetiva ou neutra e - intencionalmente ou não - afetada pela posição política e cultural daqueles que a formula. Em uma perspectiva construtivista, o julgamento final será apenas uma das muitas possibilidades e representa uma construção válida de sentido para o assunto, mas provavelmente não se estende a todos.

Há várias razões para o apoio da necessidade de se criar procedimentos de avaliação, mas, tomando emprestado a reflexão de Palumbo (2001), aparecem duas: de um lado, há a necessidade de responsabilização institucional sobre o investimento sustentado ou, em outras palavras, para tornar transparente para a comunidade (referência micro ou macro) e, dessa forma estar, respondendo a um pedido do sistema; por outro, há uma vontade, além da necessidade, um projeto concluído para constituir também uma experiência de crescimento, que é uma oportunidade de aprendizagem abrangente para o sistema que o apoia, em vista do progresso (Guichard, Huteau, 2001). Na literatura, há uma forte convergência em assimilar a fase de coleta de dados para uma pesquisa social.

O acordo entre os autores é menor sobre a perspectiva paradigmática e epistemológica a tomar. A recaída operacional é dupla: por um lado, não está claro qual paradigma seguir, consequentemente, não é clara a escolha de métodos e das técnicas.

Guba e Lincoln (1994) definem o paradigma como um conjunto de crenças fundamentais que definem a natureza do mundo e seu conhecimento, e que definem os limites da própria pesquisa, existindo quatro paradigmas-chave da investigação psicossocial contemporânea: positivismo, neopositivismo, teoria crítica e construtivismo, sintetizada em três questões fundamentais: "o que é a natureza da realidade e o que podemos saber?" (questão ontológica); "Qual é a natureza da relação entre o conhecedor e o que pode ser conhecido" (questão epistemológica); "Como pode o investigador descobrir aquilo que acha que pode ser conhecido?" (Questão metodológica)". 
Stame (2001) identifica três abordagens epistemológicas para a avaliação: positivista experimental, em que o elemento de comparação é representado pelos objetivos e avaliação para ver se e como foram alcançados; pragmática, na qual a qualidade em que você é confrontado com os padrões de qualidade e a avaliação é dar um parecer sobre a forma como abordamos as normas; e construtivista ou processo social, em que você é confrontado com o que é considerado um sucesso pelos participantes, e a avaliação é explicar porque nessa situação o resultado é considerado como tal.

Em nossa opinião, na avaliação do valor pode ser resumido como distinção entre paradigmas: "top-down" (de cima para baixo) e "bottom-up" (de baixo para cima). Tal como a abordagem pragmática pode ser aplicada em ambos os casos por meio da introdução de um elemento de comparação (interno ou externo) que permite a avaliação comparativa.

O modelo de cima para baixo e de baixo para cima são essencialmente diferentes para a presença ou ausência de hipóteses formalizadas. O primeiro modelo refere-se à falsificação de uma hipótese anteriormente formulada (Popper, 1959), definida como um conjunto interligado de conceitos, definições e proposições que fornecem uma visão sistemática dos fenômenos, especificando as relações entre as variáveis, a fim de explicar e prever o mesmo fenômeno (Kerlinger, 1964).

O segundo modelo da Grounded Theory (Strass e Corbin, 1990), de acordo com os adeptos dessa teoria, o fenômeno social não deve ser traduzido na sua essência como a variável - com seus personagens de neutralidade e objetividade - que formam a base de um complexo discurso sociológico.

Aderir ao primeiro modelo significa distinguir a fase do julgamento em duas formulações: em primeiro lugar, antes da fase de coleta de dados (formulação da hipótese) ou o estabelecimento de metas (Guichard, Huteau, 2001) e um segundo, após a fase da coleta de dados (formulação de um julgamento baseado na falsificação da hipótese com base em dados gravados).

No segundo modelo, em uma fase em que é possível ampliar a coleta de dados (também aberta a aspectos inicialmente desconhecidos, indesejados ou inesperados) é possível formular um juízo geral não vinculado à hipótese. A resiliência pode ser objeto de avaliação, se for usado adequadamente um sistema de monitorização ou simplesmente de medição.

Por exemplo, podem ser usados questionários, ou instrumentos menos estruturados, tais como a entrevista ou a entrevista semi-estruturada. Em termos práticos, se quisermos detectar o próximo nível de resistência a um treinamento em curso visando a sua valorização, temos duas possibilidades.

De acordo com o modelo de cima para baixo, deve-se inicialmente operacionalizar o conceito de resiliência (e é por isso que é fundamental ter uma matriz teórica e cultural forte), que define as características e níveis, e formular uma hipótese falsa. Em outras palavras, devemos fazer duas hipóteses: (1) o assunto tem reforçado a sua resiliência e (2) o assunto não tem reforçado a sua resiliência.

Consequentemente, é necessário articular um procedimento de coleta de dados projetado para falsificar a hipótese 1, solicitar aos indivíduos - por exemplo - certos elementos que estão na posse daqueles que têm reforçado a sua resiliência. Na base dos dados recolhidos falsificar a hipótese de acordo com um procedimento previamente definido.

De acordo com um modelo de baixo para cima, a hipótese inicial permanece implícita e está fortemente ligada a uma pluralidade de objetivos (expressos ou não) relacionados com o programa de treinamento. A fase de campo terá como objetivo detectar o maior número possível de aspectos e relações entre eles.

Por exemplo, para compreender a resiliência em termos mais amplos, deve-se considerar a esponta- 
neidade, a ética e a "nobreza" de espírito. Além disso, mediante procedimentos apropriados, vamos tentar explorar se o caminho tem causado efeitos indesejados ou não, tais como dificuldade no ambiente familiar.

\section{POR QUE AVALIAR A RESILIÊNCIA?}

O simples fato de que é possível avaliar a resiliência e ter ferramentas disponíveis que podem apoiar o processo de coleta de dados não é um convite aberto para implementar intervenções de avaliação descontroladas.

Devido à delicadeza deste processo é necessário realizar a avaliação e intervenções de monitoramento apenas para o que é estritamente necessário e tomar todas as precauções necessárias quando se trata de dimensões sensíveis sobre o assunto.

Considera-se apropriado usar uma medida de resiliência em apenas alguns casos e de forma detalhada:

- Research: em todos esses casos, a medição de tamanho pode fornecer nova informação sobre a construto ou construtos semelhantes;

- Formação: para avaliar a eficácia de um programa de treinamento no campo da resiliência, com o objetivo de melhorar e programar o caminho e não fornecer uma estimativa do efeito direto de um único assunto;

- Aconselhamento: pode ser de ajuda, como pretexto narrativo, a utilização de uma ferramenta para permitir uma avaliação direta e indireta do assunto;

- Intervenção: pode-se medir a construção de resiliência de modo a verificar (no modo longitudinal) qualquer melhoria ou deterioração do sujeito em relação à dimensão da resiliência.

Em geral, não é aconselhável sua utilização para fins de diagnóstico ou para a formulação de uma avaliação individual da construção de resiliência, por pelo menos duas razões.

Por um lado, porque os instrumentos atualmente disponíveis na literatura são facilmente falsificáveis pelas partes, em segundo lugar, porque a resistência não pode (e não deve) ser uma medida usada para expressar um juízo de valor sobre os méritos de um indivíduo. É também fortemente recomendado ter conhecimentos adequados para a utilização dos instrumentos.

\section{COMO USAR FERRAMENTAS DE MEDIÇÃO DE RESILIÊNCIA?}

Os instrumentos de medição da resiliência somente podem ser utilizados por profissionais que têm experiência e conhecimentos práticos e a competência necessária devem ter o conhecimento básico de psicometria (administração, cálculo das pontuações e retorno de resultados).

Necessariamente, deve-se conhecer a legislação quanto ao sigilo dos dados e privacidade e, consequentemente, ser capaz de informar as pessoas sobre os seus direitos e as garantias relacionadas com o tratamento de dados pessoais.

Em conformidade com os aspectos regulatórios e o quadro geral de ética, o profissional deve ser capaz de desenvolver métodos de administração, manutenção e retorno de dados inteiramente relevantes e apropriados. Além disso, o administrador deve dominar a construção de resiliência, os modelos teóricos subjacentes e ter alto nível de conhecimento em relação ao instrumento.

Por essa razão, além da profundidade necessária na construção e por meio do uso de manuais e mais 
recente literatura especializada, fazse necessário que o profissional esteja familiarizado com o instrumento, por meio de testes em um contexto apropriado. Para esse fim, é dever do administrador, na ausência de um programa de treinamento específico, desenvolver um grau adequado de treinamento durante o trabalho, antes de usar a ferramenta para fins de diagnóstico em um ambiente organizacional.

O agente de locação, especialmente nas primeiras experiências, pode aproveitar a colaboração de profissionais experientes que sabem como apoiá-lo, oferecendo garantias adequadas de profissionalismo.

Em qualquer caso, o administrador deve ser sempre plenamente consciente sobre os pontos fortes e limitações do instrumento e deve usar o instrumento apenas em situações em que considerar necessário e sempre em total conformidade com o entrevistado.

É preferível que o instrumento seja usado em grandes projetos de intervenção em que seja previsto um momento de comparação direta entre o administrador e o entrevistado por meio feedback. É recomendável que o profissional, ao usar a ferramenta pela primeira vez, ter a supervisão de um profissional com mais experiência no uso de instrumentos psicométricos.

O pesquisador deve estar ciente de que a posse ou a disponibilidade de um instrumento psicométrico não é em si uma autorização implícita para permitir seu uso livremente, pois faz-se necessário compreender e entender se deve-se ou não usá-lo, sempre considerando as limitações e as possibilidades do instrumento.

O pesquisador deve sempre ter muito claro que o instrumento é apenas uma parte da intervenção e, acima de tudo, que a intervenção é fundamentada e concretizada no feedback e não apenas na administração de um instrumento psicométrico. A administração cuidadosa não é suficiente, mas complementar a uma atenção cuidadosa e articulada.

Em termos gerais, o profissional deve usar a ferramenta dentro de ambiente adequado, no qual são garantidos níveis mínimos de privacidade e condições ambientes necessárias para a administração de um instrumento psicométrico. Por essa razão, é necessário que o ruído no ambiente seja inferior a 30 decibéis, e que esteja devidamente preparado para a pessoa um local confortável e adequado durante sua aplicação.

Portanto, é desejável que a administração do instrumento seja aplicada com tempo e lugar adequado. A confiabilidade dos dados obtidos na ausência de garantias adequadas é bastante baixa e afeta o resultado da intervenção. Os instrumentos de medição da resiliência podem ser administrados, sujeito às garantias necessárias de ajuste, seja coletivamente, seja individualmente.

No caso da administração coletiva deve-se estabelecer uma relação de 1 profissional para cada 15 entrevistados. Essa relação surge da necessidade de oferecer aos entrevistados uma pessoa especializada que pode apoiá-los na compreensão da ferramenta.

Para intervenções individuais, é necessário garantir a privacidade em relação ao assunto. Antes da administração, o profissional é obrigado a esclarecer para o entrevistado ou entrevistados o objetivo geral do instrumento, o modo de processamento de dados e as formas e os tempos estimados para o retorno do perfil individual. Também é recomendado ler as instruções contidas dentro do instrumento.

Antes da compilação, o pesquisador deve afirmar a importância de uma resposta verdadeira e honesta às perguntas contidas no instrumento. $O$ profissional deve permanecer à disposição do entrevistado (s) para responder a qualquer pergunta e, uma vez concluído o processo, deve indicar com precisão o momento e o modo de retorno do resultado.

No contexto de trabalho, é importante tranquilizar as pessoas sobre o anonimato e a impossibilidade de identificação, de qualquer forma, dos respondentes. 